REVES - Revista Relações Sociais, Vol. 04 N. 03 (2021)

https://periodicos.ufv.br/ojs/reves

doi: 10.18540/revesvl4iss3pp12736-01-10e

OPEN ACCESS - elSSN: 2595-4490

\title{
Ensino de história, música popular brasileira e relações de gênero em sala de aula: perspectivas teóricas e metodológicas
}

Teaching history, Brazilian popular music and gender relations in the classroom: theoretical and methodological perspectives

Alfredo Clodomir Rolins de Souza ${ }^{1}$ e Mary Jane Barreto de Souza ${ }^{2}$
1 Universidade Estadual de Roraima, Grupo de pesquisa: Gênero, Cultura e
$\begin{array}{lll}\text { Deslocamento, } & \text { Brasil, } & \text { E-mail: }\end{array}$ ORCID: https://orcid.org/0000-0003-3130-0084

2 Universidade Estadual de Roraima, Mestre em Educação, Grupo de pesquisa: Gênero, Cultura e Deslocamento, Brasil, Email: maryjanebarretodesouza13@gmail.com, ORCID: https://orcid.org/0000-0001-55637357

ART ICLE IN F O

Article history:

Received 2021-06-28

Accepted 2021-08-02

Available online 2021-08-02
Palavras-chave: Ensino de História. Música popular brasileira. Relações de gênero.

Keywords: History Teaching. Popular Brazilian Music. Gender relations.

RESUMO. O objetivo deste texto é fazer um relato de experiência de uma atividade que fez parte do minicurso Ensino de História, música popular brasileira e relações de gênero em sala de aula: perspectivas teóricas e metodológicas, dentro da programação da II Jornada de Gênero, Cultura e Deslocamento, da Universidade Estadual de Roraima, nos dias 15 e 16 de abril de 2021. O referido curso teve como objetivo abordar as potencialidades da música popular brasileira nas aulas de História do Brasil, para a discussão e compreensão das relações de gênero, visando a capacitação de professores e acadêmicos acerca da música enquanto expressão de um povo, como documento, linguagem, como instrumento de construção de subjetividades, como ferramenta didático-pedagógica e as possibilidades de seu uso nas aulas de História. Por sua vez a atividade aqui relatada buscou discutir a historicidade das questões de gênero, do feminismo no mundo e na sociedade brasileira. $O$ contexto em que nascem as reflexões e as demandas dos dias atuais, valendo-se dos aportes de alguns teóricos dialogando com o conteúdo de três canções brasileiras: Ai, que saudade da Amélia; Assim não dá e Triste, louca ou má. As participações nos diálogos comprovaram a eficiência da metodologia. Houve momentos de entusiasmo por parte dos/as cursistas ao constatarem o potencial da música popular brasileira, revelando-se importante documento e fonte nos estudos sobre as relações de gênero.

ABSTRACT. The objective of this text is to present an experience report of an activity that was part of the mini-course Teaching History, Brazilian Popular Music and Gender Relations in the Classroom: Theoretical and Methodological Perspectives, within the II 
Journey of Gender, Culture and Displacement, from the State University of Roraima, on April 15 and 16, 2021. The aforementioned course aimed to address the potential of Brazilian popular music in Brazilian History classes, for the discussion and understanding of gender relations, aiming at training of teachers and academics about music as an expression of a people, as a document, language, as an instrument for the construction of subjectivities, as a didactic-pedagogical tool and the possibilities of its use in History classes. In turn, the activity reported here sought to discuss the historicity of gender issues, feminism in the world and in Brazilian society. The context in which the reflections and demands of the present day are born, drawing on the contributions of some theorists dialoguing with the content of three Brazilian songs: There, I miss the Amelie; So it's not possible and Sad, crazy or bad. Participation in the dialogues proved the efficiency of the methodology. There were moments of enthusiasm on the part of the course participants when they saw the potential of Brazilian popular music, revealing itself as an important document and source in studies on gender relations.

\section{Introdução}

Este texto está inserido num contexto dos debates sobre a diversidade sociocultural que caracteriza o espaço escolar, cada vez mais discutida nos dias atuais. Entre estes temas estão incluídas as relações de gênero. Uma problemática imersa nas lutas políticas e culturais por representações, sentidos e significados presentes na sociedade, que busca enfatizar o caráter social e histórico das representações do masculino e do feminino, considerando que as concepções de gênero são constituídas nas relações sociais.

Por sua vez, o ensino de História e o seu compromisso de formação para a cidadania, não pode se eximir de refletir sobre estas questões, uma vez que as posições dos sujeitos e suas representações recebem forte influência da vivencia no espaço escolar, e dentre os vários caminhos, linguagens e estratégias pedagógicas utilizadas em sala nas discussões sobre relações de gênero, a música popular brasileira, carregada de elementos históricos, significados e representações, tem auxiliado o/a professor/a e os/as alunos/as na problematização e desnaturalização destas relações nas aulas de história.

Neste sentido, o minicurso teve como objetivo abordar as potencialidades da música popular brasileira nas aulas de História do Brasil, para a discussão e compreensão das relações de gênero, visando a capacitação de professores/as e acadêmicos acerca da música enquanto expressão de um povo, como documento, linguagem, como instrumento de construção de subjetividades, como ferramenta didático-pedagógica e as possibilidades de seu uso nas aulas de História.

Para tanto, buscou-se aproximações com os pensamentos de Manhães (2015, p. 154) quando afirma que "[...] toda arte é condicionada pelo seu tempo e representa a humanidade em consonância com as ideias, aspirações, necessidades e esperanças relativamente a uma situação histórica particular", e de Napolitano (2016, p. 11) ao afirmar que "além de ser veículo para uma boa ideia, a canção (e a música popular como um todo) também ajuda a pensar a sociedade e a história. A música não é apenas boa de ouvir, mas também é boa para pensar".

O presente texto traz no seu primeiro momento os fundamentos e aportes teóricos sobre os deslocamentos da Escola e do Ensino de História nos dias atuais, 
contexto em que emergem as questões de gênero, e o que dizem os especialistas sobre as potencialidades da música enquanto linguagem, documento e fonte da história. No tópico seguinte é feito um relato da experiência metodológica aplicada durante o minicurso aqui já referido e por último, apresentam-se as considerações finais.

\section{Para não desafinar: fundamentos}

A Escola, principalmente a pública, tem um papel fundamental no processo de construção de um país, de uma nação, de um mundo onde as pessoas não sejam julgadas e condenadas pelo que são culturalmente, por sua natureza, pela sua condição econômica e social, seu credo, seu jeito de falar, pela cor da sua pele, sexo, gênero, enfim, a escola pública deve ser concebida como um espaço de acolhimento de todas as gentes, de todos os matizes, muito embora, seja, isso é inegável, também um espaço de lutas e embates de ideias e interesses, é vista não somente como local de instrução mas também como "arena" onde se confrontam as diferentes forças sociais, econômicas, políticas e culturais em disputa pelo poder (CANDAU, 2012).

Hoje cobra-se desta instituição que ela seja, sobretudo, um espaço de diálogos entre os mais diversos universos culturais presentes na sociedade e principalmente dentro da sala de aula. Um lugar caracterizado pela pluralidade de sujeitos, de ideias, de mundos, de saberes. Deve ser compreendida como um espaço de compartilhamento de experiências individuais e coletivas, relação dos sujeitos com os diferentes saberes envolvidos na produção do saber escolar (SCHMIDT; GARCIA, 2005).

A sala de aula de História pela via acima indicada deve se transformar num espaço onde seja possível compreender como se constituíram as sociedades e a trajetória do homem e da mulher no processo de construção do mundo em que vivemos, desnaturalizando preconceitos, miséria, racismo, assim como fazer o possível para que cada aluno envolvido neste processo possa se perceber como agente e sujeito do seu tempo, enfim a história ensinada, afirma Fonseca (2009):

[...] permite que as experiências sociais sejam vistas como um constante processo de transformação; um processo que assume formas muito diferenciadas e que é produto de ações dos próprios homens. O estudo da História é fundamental para perceber o movimento e a diversidade, possibilitando comparações entre grupos e sociedades nos diversos tempos e espaços. Por isso a História ensina a ter respeito pela diferença, contribuindo para o entendimento do mundo em que vivemos e também do mundo em que gostaríamos de viver (FONSECA, 2009, p.40).

É neste cenário, em que se pensa a educação para a diversidade, para o respeito às múltiplas formas de ser, que as relações de gênero são colocadas em pauta e as aulas de História vistas como espaço para desnaturalização das concepções do masculino e do feminino, dando-lhes historicidade, além de dar visibilidade às mulheres na História. Para tanto, Pinsky (2009), ao considerar as concepções de gênero como produto das relações sociais propõe à História um olhar de gênero que "não só procura o que há de cultura nas percepções das diferenças 
sexuais como também a influência das ideias criadas a partir destas percepções na constituição das relações em geral" (PINSKY, 2009, p. 34).

Ainda segundo a referida autora:

[...] na perspectiva de gênero, o objeto da investigação não precisa ser necessariamente a categoria empírica "mulher" (ou "homem"). $\mathrm{Na}$ constituição das relações e significados de gênero, vários elementos são envolvidos: os símbolos, as normas sociais, a organização política, econômica, e social e a subjetividade (PINSKY, 2009, p. 40).

Pensando em atender a estes pressupostos é que nasce a possibilidade do uso da música popular brasileira nas aulas de História nesta perspectiva de gênero, afinal toda a nossa vida é marcada por música, ela está presente em nós desde ainda bebê, quando temos nossos sonos embalados por canções de ninar. A música agrega pessoas, junta multidões nos grandes festivais mundo afora. Seu poder de chegar até as pessoas é inegável, se tornando ótima ferramenta no processo de ensino. Enfim, "não existe linguagem mais universal que a música. Ouvimos música no ônibus, no carro, em casa, nas praças, nos estádios, nas festas, no supermercado" (DINIZ; CUNHA, 2014, P.7).

Um estudo sobre a presença das mulheres e suas representações na música popular brasileira revela a importância do protagonismo feminino neste campo da arte. Sobretudo porque a presença feminina no referido campo artístico vai de musa inspiradora à produtora, cantora e compositora. Pode se destacar também neste cenário a presença de mulheres, negras, indígenas, trans e de gays que ocupam o topo do mercado fonográfico brasileiro na atualidade.

Outra possibilidade de estudo são as biografias destas mulheres feitas a partir de documentários e livros disponíveis nas plataformas digitais para professores/as e alunos/as. No entanto o caminho mais utilizado é a exploração dos textos e contextos das canções em que as representações do feminino e das relações de gênero presentes no imaginário da sociedade podem ser identificadas, como registros históricos. Estão ali valores, costumes e hábitos do cotidiano vivido e percebido, quase sempre, inconscientes, pelos/as seus/suas autores/as e intérpretes. Segundo Napolitano (2016):

A música, sobretudo a chamada "música popular", ocupa no Brasil um lugar privilegiado na história sociocultural, lugar de mediações, fusões, encontros de diversas etnias, classes e regiões que formam o nosso grande mosaico nacional. Além disso, a música tem sido, ao menos em boa parte do século $X X$, a tradutora dos nossos dilemas nacionais e veículos de nossas utopias sociais (NAPOLITANO, 2016, p. 7).

A música popular se apresenta não só como uma ótima ferramenta e linguagem para a educação básica, mas, também como documento e fonte nos estudos históricos que o/a professor/a pode se valer nas suas aulas, em especial, quando tratar das relações de gênero. Segundo Matos (2005): 
A produção musical se apresenta como um corpo documental particularmente instigante para a análise histórica é apontada como uma das instâncias públicas em que o homem se permite falar com sinceridade sobre seus sentimentos com a relação à mulher, confessando suas angústias, medos, fraquezas, dores e desejos. Nas canções, as representações reforçam, circulam interpenetram-se, transformam-se e refletem os ideais do masculino e feminino e a sua inversão (MATOS, p. 147).

Assim a música popular, para além das boas sensações que ela nos traz, é portadora de conteúdos e significados importantíssimos para o campo das ciências humanas, e nos auxilia a compreender e refletir sobre nossa vida. Enquanto obra de arte carrega referenciais que dialogam com seu tempo. Em cada canção podemos encontrar pistas deixadas pelos/a seus/suas autores/as que nos retratam a vida cotidiana, os pensamentos, as ideias e visões de mundo. Além de ser veículo para uma boa ideia, a música popular também ajuda a pensar a sociedade e a história (NAPOLITANO 2016).

\section{As questões de gênero a partir da música popular brasileira: relatos de uma experiência teórico-metodológica}

A atividade relatada neste tópico corresponde ao primeiro momento do curso Ensino de história, música popular brasileira e relações de gênero em sala de aula: perspectivas teóricas e metodológicas, que foi realizado online, por meio do aplicativo Google Meet, nos dias 15 e 16 de abril de 2021, das 8:00 às 12:00 da manhã, totalizando uma carga horária de $8 \mathrm{~h}$ (oito) horas/aula.

A metodologia consistiu de um diálogo com os/as cursistas a partir da obra de alguns/algumas autores/as, compositores/as e intérpretes, na apresentação de slides, audição de músicas, leitura das letras de canções, de artigos, exibição de videoclipes e documentários, paralelamente acompanhados de explanações e debates.

O objetivo desta etapa foi discutir a historicidade das questões de gênero, do feminismo no mundo e na sociedade brasileira. $O$ contexto em que nascem as reflexões e as demandas dos dias atuais, valendo-se dos aportes de alguns/algumas teóricos/as dialogando com o conteúdo de três canções: Ai, que saudade da Amélia; Assim não dá e Triste, louca ou má.

Estas canções distantes uma da outra no que se refere ao tempo, se aproximam pela temática da mulher e o seu papel na sociedade. Estrategicamente colocadas numa sequência temporal que vai da década de 1940, passa pelos anos 1970 e chega aos dias atuais como forma de ilustração das mudanças na concepção e compreensão das relações de gênero no Brasil e nas sociedades ocidentais.

A primeira canção, Ai, que saudade da Amélia, interpretada por Ataúlfo Alves, composição em parceria com Mário Lago. Vejamos o que diz a letra:

Nunca vi fazer tanta exigência/Nem fazer o que você me faz/ Você não sabe o que é consciência/Não vê que eu sou um pobre rapaz/Você só pensa em luxo e riqueza/Tudo o que você vê você quer/Ai, meu Deus que saudade da Amélia/ Aquilo sim é que era mulher/Às vezes passava fome ao meu lado/E achava bonito não ter o que comer/Quando me via contrariado dizia: Meu filho, o que se há de fazer?/ Amélia não tinha a menor vaidade/Amélia 
é que era a mulher de verdade (Al, que saudade...,2013 in: Sua melhor época, CD, faixa 3)

Lançado em 1942, este samba ficou registrado no imaginário popular como retrato das relações de gênero na nossa sociedade, de um tempo e espaço hegemonicamente masculino. Os autores imprimem duas personagens femininas. Amélia, como representação da "mulher de verdade", companheira, sem vaidade, que achava bonito não ter o comer.

A outra, a esposa atual, exigente, uma mulher sem consciência, que só pensa em luxo e riqueza, tudo que vê, quer. Tal situação faz aquele "pobre rapaz" lembrarse da ex-mulher a ponto de explodir de saudades: Ai meu deus, que saudade da Amélia! Nas duas situações as mulheres aparecem como se estivessem à mercê do marido.

De imediato ao se ouvir a canção é possível imaginar a sociedade brasileira na primeira metade do século $X X$, em que o papel social da mulher, principalmente a pertencente às camadas sociais mais abastadas, se caracterizava pelas atividades domésticas, pela vida privada. O espaço público era predominantemente masculino. Mesmo as mulheres das camadas pobres que buscavam a sobrevivência em atividades nos espaços públicos, acabavam submetidas a esta hegemonia.

Segundo Biazoli- Alves (2000, p. 237) a Família e a Igreja ainda estavam falando "o que se pode considerar como um bom comportamento e o que é inaceitável para uma moça de família". Um projeto civilizatório que concebia a mulher como inferior, submissa ao homem, restando-lhes as responsabilidades da procriação, da educação dos filhos e das atividades domésticas.

Quadro este que sofrerá profundas transformações iniciadas nos períodos entre as duas grandes guerras e intensificadas nos anos de 1950 em diante. Segundo Hobsbawm (1995) entre os anos de 1950 e 1970, as mulheres ocuparam principalmente os postos no setor terciário, com uma significativa presença de casadas. Outra mudança foi o ingresso das mulheres na educação superior que se expandia e o reflorescimento do movimento feminista a partir da década de 1960.

Entre os estudiosos do tema há o consenso de que começa a se configurar um deslocamento das estruturas e dos processos centrais da sociedade moderna, "fazendo surgir novas identidades e fragmentando o indivíduo moderno, até aqui visto como um sujeito unificado" (HALL, 2011, p.7). Um marco destas transformações é o maio de 1968. Prevaleceu o "não" a tudo que se atrelava ao sistema. Estabeleceu-se ali, sobretudo, a crise da racionalidade ocidental, constituída na modernidade, incluídas as concepções de homem, mulher e família.

O mundo perdeu seus referenciais. Passando a viver numa sociedade predominantemente urbana, que colocou em xeque os valores e as estruturas que davam sustentação ao mundo moderno, e que na compreensão de Hall (2011):

[...] está fragmentando as paisagens culturais de classe, gênero, sexualidade, etnia, raça, e nacionalidade, que, no passado nos tinham fornecido sólidas localizações como indivíduos sociais. Estas transformações estão também mudando nossas identidades pessoais, abalando a ideia que temos de nós próprios como sujeitos integrados. Esta perda de um "sentido de 
si" estável é chamada, algumas vezes de deslocamento ou descentração do sujeito (HALL, 2011.p. 9).

Houve neste contexto também o deslocamento nas opções políticas, antes identificadas nas classes sociais. As fragmentou, fazendo surgir o que passou a ser chamado de política das identidades, que desnaturaliza e historiciza as diferenças, abrindo espaço para novas pautas e lutas das minorias, dos grupos oprimidos e marginalizados.

Esses movimentos tomam as identidades como fator de mobilização política. Para Hall (2011), que define a identidade como uma "celebração móvel", o feminismo faz parte daquele grupo dos novos movimentos sociais que emergiram durante os anos sessenta. Apelava às mulheres, mas também ao descentramento conceitual do sujeito cartesiano e sociológico quando questionou a clássica distinção entre o "dentro" e o "fora", o "privado" e "publico". "O slogan do feminismo era: "o pessoal é político" (HALL, 2011, p. 45)".

O feminismo politizou a forma como somos formados e produzidos sujeitos generificados, isto é, ele politizou a subjetividade, a identidade e o processo de identificação (como homens, mulheres, mães/pais, filhos/filhas). Expandiu-se para incluir a formação das identidades sexuais e de gênero. "O feminismo questionou a noção de que os homens e as mulheres eram parte da mesma identidade, a Humanidade, substituindo-a pela questão da diferença sexual". (HALL, 2011, p. 46).

Essas transformações sociais e culturais serão percebidas mundo afora e no Brasil. Notam-se alterações nas constituições familiares e no papel da mulher na sociedade. Há sinais destas mudanças nas letras de algumas canções como em Assim não dá, de Ana Maria Martins Nóbrega, gravada em 1973, pela cantora Simone. Vejamos o diz a letra da canção:

\begin{abstract}
Assim não dá/ Assim não dá mais pé/ É tanto tempo longe/Eu já nem sei quem você é/Sempre a nossa casa está vazia/Minhas noites são tão frias/ Minha vida passa por passar/ Fico assim sozinha o dia inteiro/Sua estrada, companheiro/Bifurcou pra outro lugar Assim não dá/Assim não dá mais pé/O seu negócio é curtição/O meu como é que é?/ Seu caso é boemia/É madrugada/Mas cadê a empregada/Pra cuidar dos nossos filhos? Meus/É tanta coisa que separa o namorado/ Do senhor mais bem casado/ Que a música escolheu/Assim não dá/ Assim não dá mais pé/Você se esquece é de cantar sua mulher/Você se esquece é de cantar uma mulher/ Você se esquece é de cantar esta mulher (ASSIM não dá, 1973, in: Simone, formato digital, faixa 7).
\end{abstract}

A música é um samba. Um estilo musical bastante consumido pelas camadas populares, ou seja, é uma mensagem que chega a muitas pessoas e pode representar a condição e a posição de muitas mulheres país afora. O próprio título já sugere uma reação feminina às desvantagens nas relações de gênero.

A letra sugere um diálogo entre a esposa e o marido que optou pela noite, a música e a boemia e recebe o ultimato da mulher, cansada de ficar sozinha, dos cuidados da casa e dos filhos: "Assim não dá, assim não dá mais pé, o seu negócio é curtição, o meu como é que é?". 
Mesmo que em algumas partes do mundo, a exemplo do bloco socialista europeu ou mesmo o Brasil, estas mudanças não tenham chegado com a mesma intensidade que na Inglaterra e nos EUA o fato é que quando se caminha para o fim do século XX a chamada crise da família tradicional, a autonomia da mulher e a defesa das liberdades sexuais estarão na pauta do dia. E segundo Hobsbawm (1995) :

A crise da família estava relacionada com mudanças bastante dramáticas nos padrões públicos que governam a conduta sexual, a parceria e a procriação. Eram tanto oficiais quanto não oficiais, e a grande mudança em ambas está datada, coincidindo com as décadas de 1960 e 1970. Oficialmente, essa foi uma era de extraordinária liberalização tanto para os heterossexuais (isto é, sobretudo para as mulheres que gozavam de muito menos liberdade que os homens) quanto para os homossexuais, além de outras formas de dissidência cultural-sexual (HOBSBAWM, 1995, p. 316).

Chegado o século $X X I$ a representação do feminino já não está mais ligada unicamente ao universo doméstico. A Amélia, mulher sem vaidade, não define mais a "mulher de verdade". Pode-se arriscar que talvez nunca tenha definido e não será o homem ou marido quem a definirá. Nos versos de Triste, louca ou má, canção da banda Francisco El hombre, parece uma resposta à Amélia e soa como um manifesto: "Eu não me vejo na palavra fêmea, alvo de caça, conformada vítima. Ela desatinou, desatou nós, vai viver só". Expõe claramente uma nova representação da mulher na sociedade brasileira. Vejamos a letra:

\begin{abstract}
Triste, louca ou má/Será qualificada/Ela quem recusar/Seguir receita tal/A receita cultural/ Do marido, da família/Cuida, cuida da rotina/Só mesmo, rejeita/Bem conhecida receita/Quem não sem dores/Aceita que tudo deve mudar/Que um homem não te define/Sua casa não te define/Sua carne não te define/Você é seu próprio lar/ Ela desatinou, desatou nós/ Vai viver só/Eu não me vejo na palavra/Fêmea, alvo de caça/Conformada vítima/Prefiro queimar o mapa/Traçar de novo a estrada/Ver cores nas cinzas/E a vida reinventar/ $\mathrm{E}$ um homem não me define/ Minha casa não me define/ Minha carne não me define/Eu sou meu próprio lar (TRISTE, louca ou má, 2017, in: Francisco el hombre, formato digital, faixa 1).
\end{abstract}

A partir da canção não é difícil perceber que as relações de gênero, identidades e representações, são constituídas nas relações de poder, dentro de sistemas de significações, de espaços de construção de subjetividades, nas relações sociais como a família, mas, sobretudo, a educação escolar, revelando, portanto, as "implicações pedagógicas e curriculares dessas conexões entre identidade e representação" (SILVA, 2014, p. 91-92). Como se pode perceber, "a música tem sido umas das bases de formação social que traduz, em sua métrica, maneira de perceber a mulher em diferentes contextos, significação e representação" (MANHÃES, 2015, p.145). 


\section{Considerações finais}

Buscou-se neste relato trazer alguns pressupostos teóricos e metodológicos que fundamentam a aproximação entre o Ensino de História, música popular brasileira e relação de gênero. Demonstrou-se, conforme ministrado no minicurso aqui referido, as possibilidades de diálogo entre estes campos do conhecimento. Referencias que podem auxiliar o/a professor/a e os/as alunos/as na problematização e desnaturalização das diferenças sexuais nas aulas de história valendo-se das potencialidades históricas da música popular, como documento e fonte ou mesmo como linguagem. As muitas intervenções e participações nos diálogos durante o minicurso comprovaram a eficiência da metodologia aqui descrita. Houve momentos de muito entusiasmo e de emoção por parte dos/as cursistas, surpresos/as ao constatarem o potencial da música popular brasileira como tradutora dos dilemas cotidianos, registro de sentimentos, valores e costumes da sociedade, revelando-se importante documento e fonte nos estudos sobre as relações de gênero.

\section{Referências}

Al, que saudade da Amélia. Intérprete: Ataúlfo Alves. Compositores: Ataúlfo Alves e Mário Lago. in: SUA melhor época. Intérprete: Ataúlfo Alves. [s.]: NS, 2013. 1 CD (45min 52s). Faixa 3.

ALBUQUERQUE JÚNIOR, Durval Muniz de. 0 tecelão dos tempos: novos ensaios de teoria em história. São Paulo: Intermeios, 2019. 276 p.

ASSIM não dá. Intérprete: Simone. Compositora: Ana Maria Martins Nóbrega. In: Simone. Intérprete: Simone. [s.]: EMI Music Brasil Ltda, 1973. Formato digital (33min27s). Faixa 7. Disponível em: https://www.spotify.com/br Acesso em: 16 de jun. de 2021.

BIASOLI-ALVES, Zélia Maria Mendes. Continuidades e rupturas no papel da mulher brasileira no século XX. Revista Psicologia: Teoria e Pesquisa, v. 16, n.3, p.233239, $2000 . \quad$ Disponível em: https://www.scielo.br///ptp/a/kj9szysyT59MGzyQc3d7xnf/?lang=pt Acesso em 14 de jun. de 2021.

DINIZ, André; CUNHA, Diogo. A república cantada: do choro ao funk, a história do Brasil através da música. Rio de janeiro: Zahar,2014. 179 p.

FONSECA, Selva Guimarães. Didática e prática de ensino em História: experiências, reflexões e aprendizados. Campinas, SP: Papirus, 2009.

HALL, Stuart. A identidade cultural na pós-modernidade. 11. Ed. Rio de Janeiro: DP\&A, 2011.

HOBSBAWN, Eric. Era dos extremos: o breve século XX (1914/1991). São Paulo: Companhia das Letras, 1995.

MANHÃES, Manuela Carla. Os personagens femininos na música popular brasileira. Cadernos do CNLF. v. XIX, n. 12, CiFEFiL, p. 145- 159, 2015. Disponível em: http://www.filologia.org.br/xix cnlf/cnlf/12/012.pdf Acesso em 14 de jun. de 2021.

MATOS, Maria Izilda Santos de. Âncoras de emoções: corpos, subjetividade e sensibilidade. Bauru, SP: Edusc, 2005. 182p.

NAPOLITANO, Marcos. História e música. 3 ed. Belo Horizonte: Autêntica, 2016. PINSKY, Carla Bassanezi. Gênero. In: PINSKY, Carla Bassanesi. (Org.). Novos temas nas aulas de história. São Paulo: Contexto, 2009. p. 29-54.

SILVA, Tomaz Tadeu. A produção social da identidade e da diferença. In SILVA, Tomaz Tadeu; HALL, Stuart, WOODWARD, Kathryn. (Org.) Identidade e diferença: a perspectiva dos estudos culturais. 15 ed. Petrópolis, RJ: Vozes, 2014. p. $73-102$. 
SCHMIDT, Maria Auxiliadora; GARCIA, Tania Maria. A formação da consciência histórica de alunos e professores e o cotidiano em aulas de história. Cadernos Cedes. Campinas. v. 25. n. 67.p. 297 a 368. Set/ dez, 2005. Disponível em: http/www.cedes.unicamp.br.

TRISTE, Louca ou má. Intérprete: Francisco El hombre. Compositor: Francisco El hombre, in: O OUTRO lado do paraíso, intérprete: Francisco El hombre [s.], Som livre, 2017, formato digital. Faixa 1. Disponível em: https://www.spotify.com/br. Acesso em: 16 de jun. de 2021. 